\title{
Correction to: A comparison of full-field and anomaly initialization for seasonal prediction of Indian Ocean basin mode
}

\author{
Shuai $\mathrm{Hu}^{1,2} \cdot \mathrm{Bo} \mathrm{Wu}^{1}$ (D) $\cdot$ Tianjun Zhou ${ }^{1} \cdot$ Zhun Guo $^{1}$
}

Published online: 30 August 2019

(c) Springer-Verlag GmbH Germany, part of Springer Nature 2019

\author{
Correction to: Climate Dynamics \\ https://doi.org/10.1007/s00382-019-04916-9
}

The article, "A comparison of full-field and anomaly initialization for seasonal prediction of Indian Ocean basin mode", written by Bo Wu was originally published electronically on the publisher's internet portal (currently SpringerLink) on 09 August 2019 with open access.

With the author(s)' decision to step back from Open Choice, the copyright of the article changed on September 2019 to $($ C Springer-Verlag GmbH Germany, part of Springer Nature 2019 and the article is forthwith distributed under the terms of copyright.

The original article was corrected.

Publisher's Note Springer Nature remains neutral with regard to jurisdictional claims in published maps and institutional affiliations.

The original article can be found online at https://doi.org/10.1007/ s00382-019-04916-9.

Bo Wu

wubo@mail.iap.ac.cn

1 LASG, Institute of Atmospheric Physics, Chinese Academy of Science, Beijing 100029, China

2 University of Chinese Academy of Sciences, Beijing 100049, China 